\title{
Article \\ State-Level Health Disparity Is Associated with Sarcoidosis Mortality
}

\author{
Yu-Che Lee ${ }^{1}$ (D), Ko-Yun Chang ${ }^{2}$ and Mehdi Mirsaeidi ${ }^{3,4, *(D)}$ \\ 1 Department of Medicine, University at Buffalo-Catholic Health System, Buffalo, NY 14220, USA; \\ yuchelee@buffalo.edu \\ 2 Division of Chest Medicine, Taichung Veterans General Hospital, Taichung 40705, Taiwan; \\ karen71531@gmail.com \\ 3 Division of Pulmonary and Critical Care Medicine, University of Miami Miller School of Medicine, \\ Miami, FL 33146, USA \\ 4 Section of Pulmonary Medicine, Miami Veterans Affairs Healthcare System, Miami, FL 33125, USA \\ * Correspondence: msm249@med.miami.edu
}

Citation: Lee, Y.-C.; Chang, K.-Y.; Mirsaeidi, M. State-Level Health Disparity Is Associated with Sarcoidosis Mortality. J. Clin. Med. 2021, 10, 2366. https://doi.org/ $10.3390 /$ jcm 10112366

Academic Editors: Teen-Hang Meen, Fukuyama Yoshiyasu, Charles Tijus and Po-Lei Lee

Received: 19 April 2021

Accepted: 26 May 2021

Published: 27 May 2021

Publisher's Note: MDPI stays neutral with regard to jurisdictional claims in published maps and institutional affiliations.

Copyright: (C) 2021 by the authors Licensee MDPI, Basel, Switzerland. This article is an open access article distributed under the terms and conditions of the Creative Commons Attribution (CC BY) license (https:// creativecommons.org/licenses/by/ $4.0 /)$.
Abstract: Background: Sarcoidosis is associated with significant morbidity and rising health care utilization, which contribute to the health care burden and disease outcome. In the United States (US), evaluation of sarcoidosis mortality by individual states has not been investigated. Methods: We examined sarcoidosis mortality data for 1999-2018 from the Centers for Disease Control and Prevention (CDC). America's Health Rankings (AHR) assesses the nation's health on a state-by-state basis to determine state health rankings. The numbers of certified Sarcoidosis Clinics within the US were obtained from World Association for Sarcoidosis and Other Granulomatous Disorders (WASOG) and Foundation for Sarcoidosis Research (FSR). The associations between sarcoidosis mortality and state health disparities were calculated by linear regression analyses. Results: From 1999 to 2018, the mean age-adjusted mortality rate (AAMR) in all populations, African Americans and European Americans were 2.9, 14.8, and 1.4 per 1,000,000 population, respectively. South Carolina had the highest AAMR for all populations (6.6/1,000,000) and African Americans $(20.8 / 1,000,000)$. Both Utah and Vermont had the highest AAMR for European Americans (2.6/1,000,000). New York State and South Atlantic had the largest numbers of FSR-WASOG Sarcoidosis Clinics (6 and 13, respectively). States with better health rankings were significantly associated with lower AAMR in all population $\left(R^{2}=0.170, p=0.003\right)$ but with higher AAMR in European Americans $\left(R^{2}=0.223\right.$, $p<0.001)$. Conclusions: There are significant variations in sarcoidosis mortality within the US. Sarcoidosis mortality was strongly associated with state health disparities. The current study suggests sarcoidosis mortality could be an indicator to reflect the state-level health care disparities in the US.

Keywords: USA; health disparity; sarcoidosis; mortality

\section{Introduction}

Sarcoidosis is a multisystem granulomatous disease of unknown origin that mainly affects lungs, lymph nodes, skin, and eyes [1]. Racial and geographic disparities in sarcoidosis epidemiology, disease course, and prognosis have been well described, indicating African Americans and northern European countries are most affected worldwide [2]. In the United States (US), the differences in sarcoidosis incidence and mortality rates between races have been reported with African Americans consistently having higher rates than European Americans. African Americans have a 3-5 fold greater incidence of sarcoidosis and a 10-12 fold greater mortality rate compare to European Americans [3,4]. Geographic variabilities of sarcoidosis-related mortality in the US have also been documented with the highest rate in the southern region for all population, the Midwest for African Americans females, and New England states for European Americans [3-6]. 
Sarcoidosis is associated with significant morbidity and rising health care utilization, which contribute to the health care burden and disease outcome $[7,8]$. Despite previous studies discussing the epidemiology and outcome of sarcoidosis, no study has evaluated the role of the state-level health disparity in mortality. We hypothesized that sarcoidosis-related mortality will be correlated with state health rankings and the accessibility of sarcoidosis medical centers, which reflect the health care disparities between states. We evaluated the association of sarcoidosis-related mortality, state health rankings, and numbers of sarcoidosis medical centers to provide a general overview of the relationship between mortality and health care disparities in the US.

\section{Methods}

\subsection{Data Resources and Study Design}

Mortality data for 1999-2018 were obtained from the Centers for Disease Control and Prevention, Wide-ranging Online Data for Epidemiologic Research (CDC WONDER). Data are based on death certificates for US residents and sarcoidosis-related mortality was defined as all decedents with International Classification of Diseases, 10th Revision (ICD-10) D86 codes as the underlying cause of death. Age-adjusted mortality rates (AAMR) per 1,000,000 population per year were generated from CDC WONDER based on weighting averages of the age-specific death rates and comparing with relative mortality risk among 2000 US standard populations.

America's Health Rankings (AHR) was built in 1990 and partnered with the United Health Foundation and the American Public Health Association. AHR assesses the nation's health on a state-by-state basis with different measures to determine the 50 US states' health rankings annually, with " 1 " being the healthiest state and " 50 " the least healthy state. The state health rankings are a composite index of health measures and calculated by adding each ranked component multiplied by its assigned weight in five core measures (four groups of health Determinants and one health Outcomes): 25\% for Behaviors (drug death, excessive drinking, high school graduation, obesity, physical inactivity, smoking), $22.5 \%$ for Community \& Environment (air pollution, children in poverty, infectious disease, chlamydia, pertussis, salmonella, occupational fatalities, violent crime), $12.5 \%$ for Policy (immunization, public health funding, uninsured), 15\% for Clinical Care (dentists, low birth weight, mental health providers, preventable hospitalizations, primary care physicians), and $25 \%$ for Outcomes (cancer deaths, cardiovascular deaths, diabetes, disparity in mental status, frequent in mental \& physical distress, infant mortality, premature death). We obtained twenty-year averages of Overall health value, All Determinants value, and All Outcomes value from AHR and calculated the state health rankings for 1999-2018 respectively.

World Association for Sarcoidosis and Other Granulomatous Disorders (WASOG) is a unique organization for the diagnosis and treatment of sarcoidosis and related conditions. WASOG partnered with the Foundation for Sarcoidosis Research (FSR) to provide a platform recognizing institutions as certified Sarcoidosis Clinics. We obtained the numbers of certified Sarcoidosis Clinics within the US from WASOG and divided them into 2 groups (states with and without Sarcoidosis Clinics) and 9 geographic divisions defined by the United States Census Bureau.

\subsection{Statistical Analysis}

We thereafter generated scatterplots of Overall health rankings, All Determinants health rankings, All Outcome health rankings by state, and Sarcoidosis Clinics numbers versus Sarcoidosis AAMR, respectively. Univariate linear regression analyses were performed using the following formulas to evaluate the association between sarcoidosis AAMR, state health rankings, and Sarcoidosis Clinics: Sarcoidosis AAMR $=$ Overall Health Rankings $\times \beta+\alpha$; Sarcoidosis AAMR $=$ All Determinants health rankings $\times \beta+\alpha$; Sarcoidosis AAMR $=$ All Outcome health rankings $\times \beta+\alpha$; Sarcoidosis AAMR $=$ States with or without Sarcoidosis Clinics $\times \beta+\alpha$; Sarcoidosis AAMR $=$ Sarcoidosis Clinics numbers $\times \beta$ 
$+\alpha$. Statistical analyses and data management were performed using Statistics Software $S A S^{\circledR}$ (SAS Institute, Cary, NC, USA) and Microsoft Excel (Redmond, WA, USA), with $p$-Values $<0.05$ in two-sided $T$-tests to indicate statistical significance.

\section{Results}

\subsection{Sarcoidosis Mortality Rates by State}

From 1999 to 2018, a total of 50,567,774 deaths occurred in the US, and sarcoidosis was documented as the underlying cause of death in 18,877 decedents (10,922 for African Americans, 7765 for European Americans, 131 for Asian or Pacific Islander, and 59 for American Indian or Alaska Native). The overall 20-year sarcoidosis-related AAMR in all populations, African Americans and European Americans were 2.9, 14.8, and 1.4 per $1,000,000$ population, respectively. There was a remarkable geographic variation in AAMR by race. The highest AAMR for all populations was recorded in South Carolina (6.6 per $1,000,000)$ and the lowest in Arizona (1.0 per 1,000,000). South Carolina also had the highest AAMR for African Americans (20.8 per 1,000,000) and Nevada had the lowest AAMR for African Americans (7.1 per 1,000,000). For European Americans, the lowest AAMR was also reported in Arizona $(0.8$ per $1,000,000)$ and the highest in both Utah and Vermont $(2.6$ per 1,000,000). Table 1 summarizes the results and Figure 1 shows the sarcoidosis-related AAMR in African Americans and European Americans by state for 1999-2018.

Table 1. Summary of State Health Rankings, Sarcoidosis-Related Age-Adjusted Mortality Rate, and FSR-WASOG (Foundation for Sarcoidosis Research-World Association for Sarcoidosis and Other Granulomatous Disorders) Sarcoidosis Clinics of 50 States.

\begin{tabular}{|c|c|c|c|c|c|c|c|}
\hline \multirow{2}{*}{ State } & \multicolumn{3}{|c|}{$\begin{array}{c}\text { 1999-2018 } \\
\text { America's Health Rankings (AHR) }\end{array}$} & \multicolumn{3}{|c|}{$\begin{array}{c}1999-2018 \\
\text { Age-Adjusted Mortality Rate (AAMR) Per } \\
1,000,000\end{array}$} & \multirow{2}{*}{$\begin{array}{c}\text { FSR-WASOG } \\
\text { Sarcoidosis Clinics }\end{array}$} \\
\hline & Overall & All Outcomes & $\begin{array}{l}\text { All } \\
\text { Determinants }\end{array}$ & $\begin{array}{c}\text { All } \\
\text { Population }\end{array}$ & $\begin{array}{c}\text { African } \\
\text { Americans }\end{array}$ & $\begin{array}{l}\text { European } \\
\text { Americans }\end{array}$ & \\
\hline Hawaii & 1 & 1 & 6 & No Data & No Data & No Data & 0 \\
\hline Minnesota & 2 & 2 & 5 & 1.9 & 14.3 & 1.6 & 2 \\
\hline Vermont & 3 & 12 & 1 & 2.7 & No Data & 2.6 & 0 \\
\hline Utah & 4 & 3 & 7 & 2.7 & No Data & 2.6 & 1 \\
\hline New Hampshire & 5 & 6 & 3 & 1.6 & No Data & 1.6 & 0 \\
\hline Massachusetts & 6 & 7 & 2 & 2.1 & 11.1 & 1.6 & 2 \\
\hline Connecticut & 7 & 8 & 4 & 2.7 & 15.4 & 1.6 & 1 \\
\hline Colorado & 8 & 4 & 11 & 1.8 & 13.6 & 1.4 & 1 \\
\hline North Dakota & 9 & 5 & 14 & Unreliable & No Data & Unreliable & 0 \\
\hline Washington & 10 & 10 & 12 & 2.2 & 15.2 & 1.9 & 0 \\
\hline Iowa & 11 & 9 & 16 & 1.6 & 16.6 & 1.3 & 1 \\
\hline Nebraska & 12 & 13 & 13 & 1.6 & No Data & 1.3 & 0 \\
\hline Rhode Island & 13 & 26 & 9 & 2.2 & No Data & 2.0 & 0 \\
\hline Maine & 14 & 27 & 8 & 2.5 & No Data & 2.5 & 0 \\
\hline Idaho & 15 & 11 & 20 & 1.7 & No Data & 1.6 & 0 \\
\hline Wisconsin & 16 & 17 & 15 & 2.8 & 19.6 & 1.9 & 0 \\
\hline New Jersey & 17 & 23 & 10 & 3.5 & 17.4 & 1.5 & 2 \\
\hline Oregon & 18 & 19 & 18 & 1.7 & No Data & 1.6 & 0 \\
\hline South Dakota & 19 & 14 & 22 & 1.6 & No Data & 1.6 & 0 \\
\hline California & 20 & 16 & 21 & 1.6 & 11.7 & 1.0 & 3 \\
\hline Virginia & 21 & 28 & 17 & 4.3 & 17.8 & 1.4 & 3 \\
\hline Kansas & 22 & 25 & 23 & 2.4 & 16.6 & 1.7 & 1 \\
\hline Montana & 23 & 22 & 24 & 1.6 & No Data & 1.7 & 0 \\
\hline Wyoming & 24 & 18 & 26 & 1.9 & No Data & Unreliable & 0 \\
\hline Maryland & 25 & 31 & 19 & 5.8 & 17.5 & 1.5 & 1 \\
\hline New York & 26 & 24 & 25 & 3.4 & 12.9 & 1.7 & 6 \\
\hline Alaska & 27 & 15 & 36 & 2.8 & No Data & 2.3 & 0 \\
\hline Pennsylvania & 28 & 33 & 27 & 3.2 & 19.3 & 1.6 & 3 \\
\hline Arizona & 29 & 20 & 33 & 1.0 & 10.5 & 0.8 & 2 \\
\hline Illinois & 30 & 32 & 28 & 3.1 & 15.4 & 1.2 & 4 \\
\hline Michigan & 31 & 35 & 29 & 4.0 & 18.4 & 1.9 & 3 \\
\hline Delaware & 32 & 36 & 30 & 4.7 & 18.1 & 1.8 & 0 \\
\hline New Mexico & 33 & 21 & 42 & 1.1 & No Data & 1.0 & 0 \\
\hline Ohio & 34 & 38 & 31 & 3.2 & 16.0 & 1.7 & 3 \\
\hline
\end{tabular}


Table 1. Cont.

\begin{tabular}{|c|c|c|c|c|c|c|c|}
\hline \multirow{2}{*}{ State } & \multicolumn{3}{|c|}{$\begin{array}{c}\text { 1999-2018 } \\
\text { America's Health Rankings (AHR) }\end{array}$} & \multicolumn{3}{|c|}{$\begin{array}{c}1999-2018 \\
\text { Age-Adjusted Mortality Rate (AAMR) Per } \\
1,000,000\end{array}$} & \multirow{2}{*}{$\begin{array}{c}\text { FSR-WASOG } \\
\text { Sarcoidosis Clinics }\end{array}$} \\
\hline & Overall & All Outcomes & $\begin{array}{c}\text { All } \\
\text { Determinants }\end{array}$ & $\begin{array}{c}\text { All } \\
\text { Population }\end{array}$ & $\begin{array}{c}\text { African } \\
\text { Americans }\end{array}$ & $\begin{array}{l}\text { European } \\
\text { Americans }\end{array}$ & \\
\hline Florida & 35 & 30 & 37 & 2.4 & 11.0 & 1.1 & 3 \\
\hline North Carolina & 36 & 37 & 32 & 5.3 & 20.5 & 1.5 & 3 \\
\hline Texas & 37 & 29 & 40 & 2.1 & 11.1 & 1.0 & 4 \\
\hline Indiana & 38 & 40 & 35 & 2.4 & 15.3 & 1.4 & 0 \\
\hline Missouri & 39 & 41 & 34 & 2.5 & 14.7 & 1.2 & 1 \\
\hline Georgia & 40 & 39 & 38 & 4.7 & 13.7 & 1.4 & 2 \\
\hline Nevada & 41 & 34 & 45 & 1.5 & 7.1 & 1.2 & 0 \\
\hline Kentucky & 42 & 46 & 39 & 2.2 & 12.8 & 1.4 & 0 \\
\hline South Carolina & 43 & 42 & 47 & 6.6 & 20.8 & 1.8 & 1 \\
\hline Tennessee & 44 & 43 & 43 & 3.2 & 14.1 & 1.3 & 2 \\
\hline Oklahoma & 45 & 44 & 46 & 1.9 & 14.3 & 0.9 & 2 \\
\hline West Virginia & 46 & 48 & 41 & 2.1 & 20.2 & 1.6 & 0 \\
\hline Alabama & 47 & 49 & 44 & 5.3 & 17.5 & 1.6 & 1 \\
\hline Arkansas & 48 & 45 & 48 & 2.9 & 13.9 & 1.1 & 0 \\
\hline Louisiana & 49 & 47 & 50 & 4.5 & 12.0 & 1.4 & 2 \\
\hline Mississippi & 50 & 50 & 49 & 5.0 & 12.4 & 1.2 & 0 \\
\hline
\end{tabular}

\subsection{Association between State Heath Rankings and Sarcoidosis-Related AAMR}

Table 1 and Figure S1 in the Supplementary Materials show the health rankings for 50 states from 1999 to 2018 in three different categories: Overall health rankings, All Determinants health rankings, and All Outcomes health rankings. Among 50 states, Hawaii had both the highest Overall and All Outcomes health ranking and Mississippi had both the lowest Overall and All Outcomes health ranking. Regarding All Determinants health rankings, Vermont was the healthiest and Louisiana was the least healthy. States with better Overall, All Outcomes and All Determinants health rankings were significantly associated with lower sarcoidosis-related AAMR in all population $\left(R^{2}=0.170, p=0.003 ; R^{2}=0.286\right.$, $p<0.001 ; R^{2}=0.095, p=0.033$, Figure 2) whereas an opposite association was found in European Americans $\left(R^{2}=0.223, p<0.001 ; R^{2}=0.095, p=0.035 ; R^{2}=0.248, p<0.001\right.$, Figure 3). There was no association between health rankings and sarcoidosis-related AAMR in African Americans $\left(R^{2}=0.023, p=0.389 ; R^{2}=1.66 \times 10^{-5}, p=0.981 ; R^{2}=0.044, p=0.226\right.$, Figure 4).

\subsection{Association between Sarcoidosis Clinics and Sarcoidosis-Related AAMR}

Tables 1 and 2, and Figure S2 in the Supplementary Materials show the numbers of Sarcoidosis Clinics and sarcoidosis-related AAMR for each state and 9 geographic divisions. Among 50 states, New York had the largest number of Sarcoidosis Clinics (6). States with Sarcoidosis Clinics had 0.9 per 1,000,000 higher AAMR compared to those without Sarcoidosis Clinics in all population $(p=0.018)$, but there was no statistical difference in European Americans $(p=0.08)$ and African Americans $(p=0.88)$. Regarding geographic divisions, South Atlantic had the largest numbers of Sarcoidosis Clinics (13), the highest AAMR $(4.2$ per 1,000,000) for all population, and the second highest AAMR $(16.3$ per 1,000,000) for African Americans. In contrast, New England had the smallest number of Sarcoidosis Clinics (3) but the highest AAMR (1.8 per 1,000,000) for European Americans. Divisions with larger numbers of Sarcoidosis Clinics were associated with higher AAMR in all population and African Americans $\left(R^{2}=0.454, p=0.047 ; R^{2}=0.447\right.$, $p=0.049$, respectively, Figure S3 in the Supplementary Materials). There was no association between Sarcoidosis Clinics and AAMR in European Americans $(p=0.99)$. 
(A)

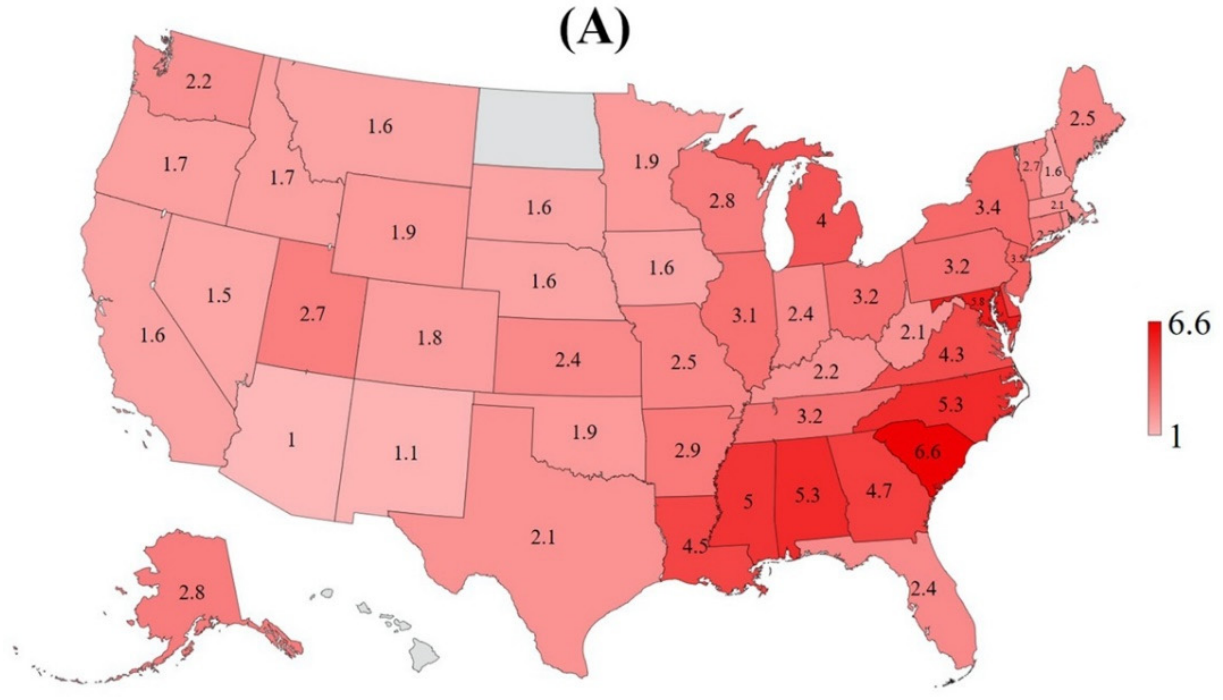

(B)

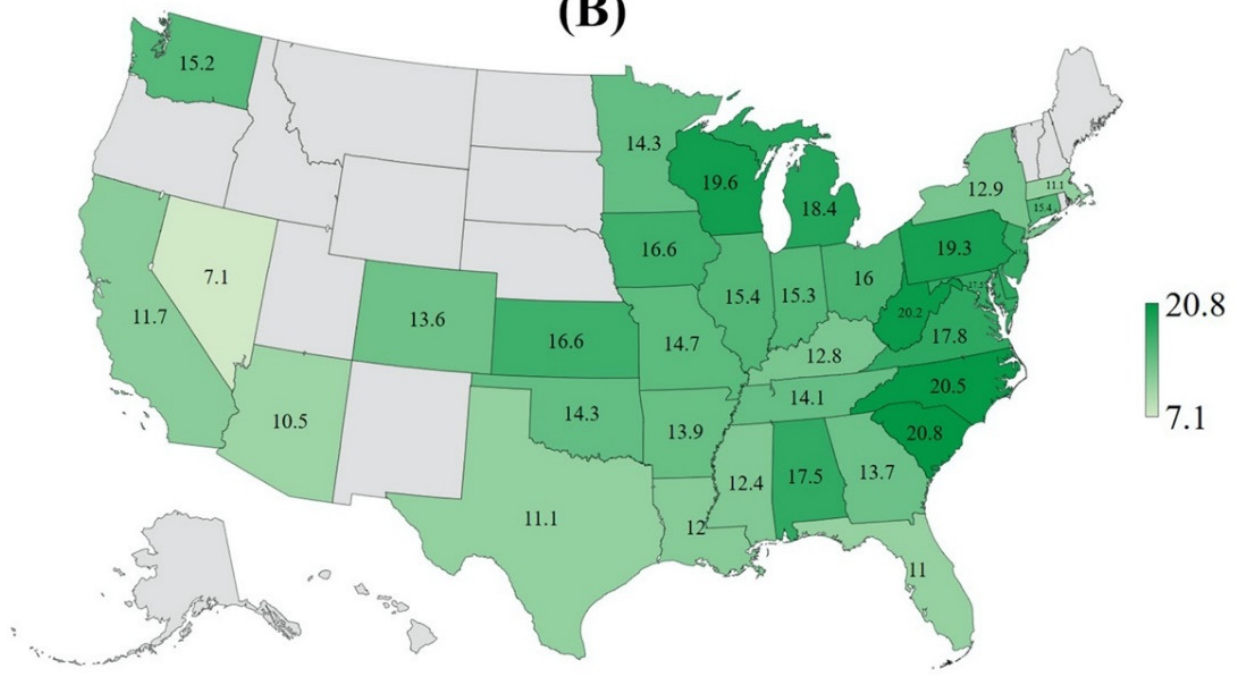

(C)

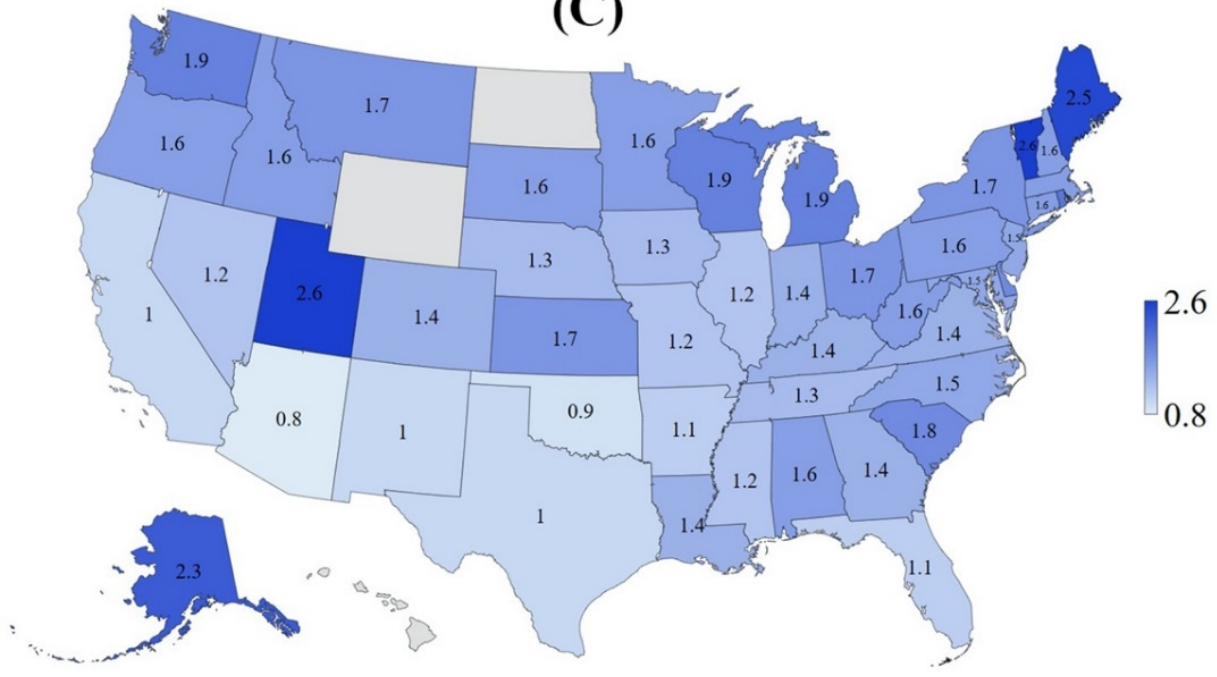

Figure 1. Map of Sarcoidosis-Related AAMR (age-adjusted mortality rate) per 1,000,000 for (A) All Population, (B) African Americans, and (C) European Americans for 50 States of the US, 1999 to 2018. 


\section{All Population}

(A) Sarcoidosis-Related AAMR and Overall Health Ranking

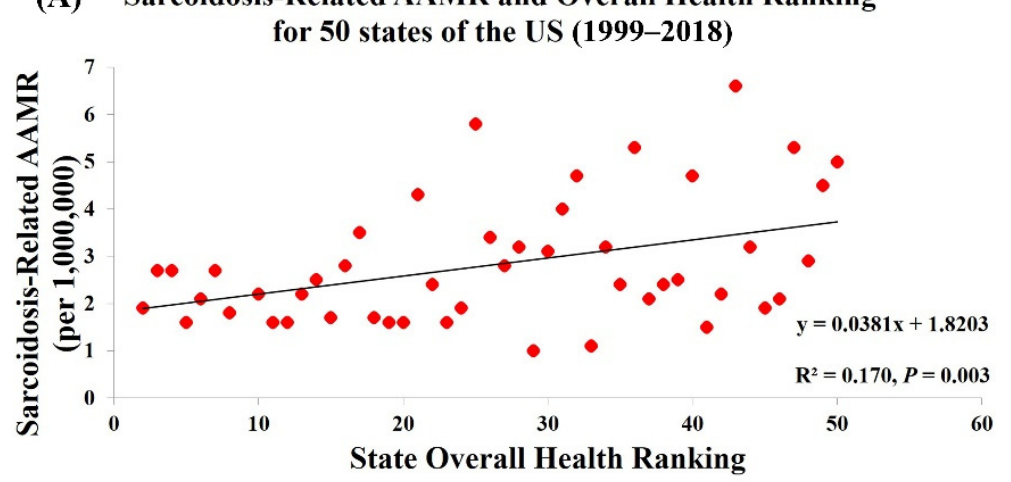

(B) Sarcoidosis-Related AAMR and All Outcomes Health

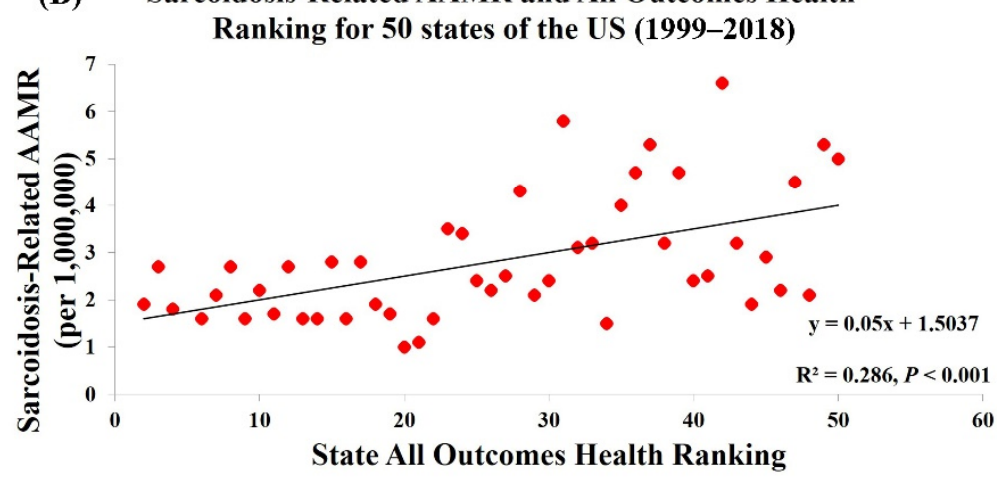

(C) Sarcoidosis-Related AAMR and All Determinants Health Ranking for 50 states of the US (1999-2018)

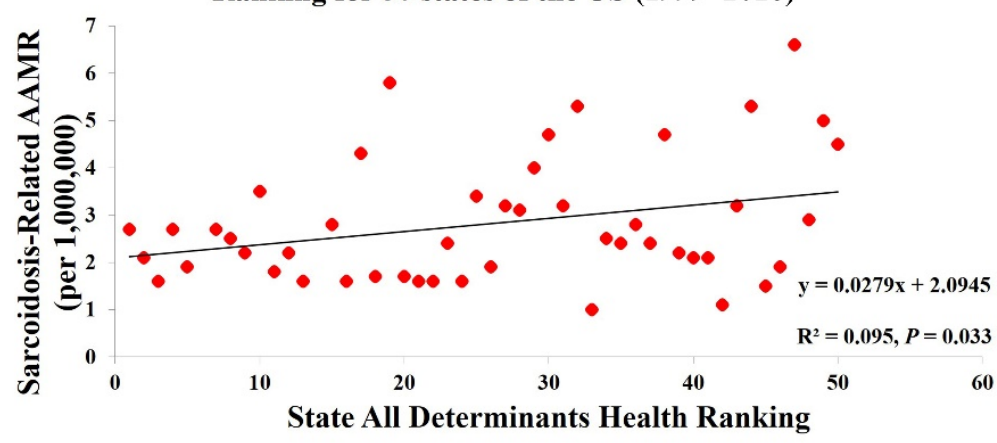

Figure 2. Sarcoidosis-Related AAMR in All Population are significantly associated with (A) Overall Health Rankings, (B) All Outcomes Health Rankings, and (C) All Determinants Health Rankings. 


\section{European Americans}

(A) Sarcoidosis-Related AAMR and Overall Health Ranking for 50 states of the US (1999-2018)

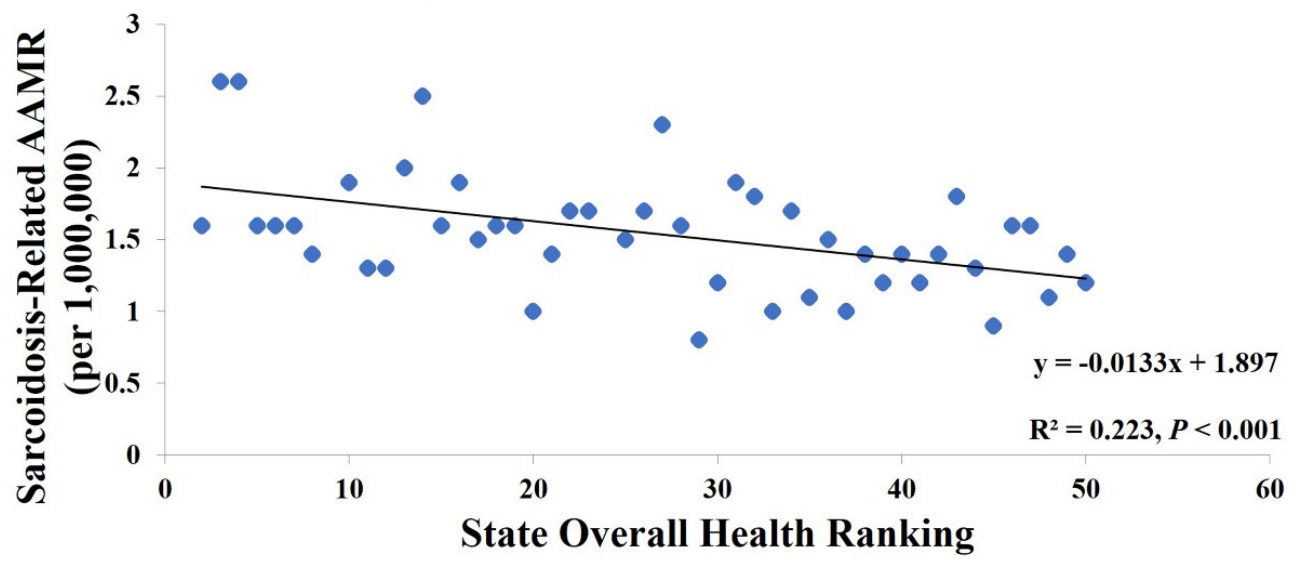

(B) Sarcoidosis-Related AAMR and All Outcomes Health Ranking for 50 states of the US (1999-2018)

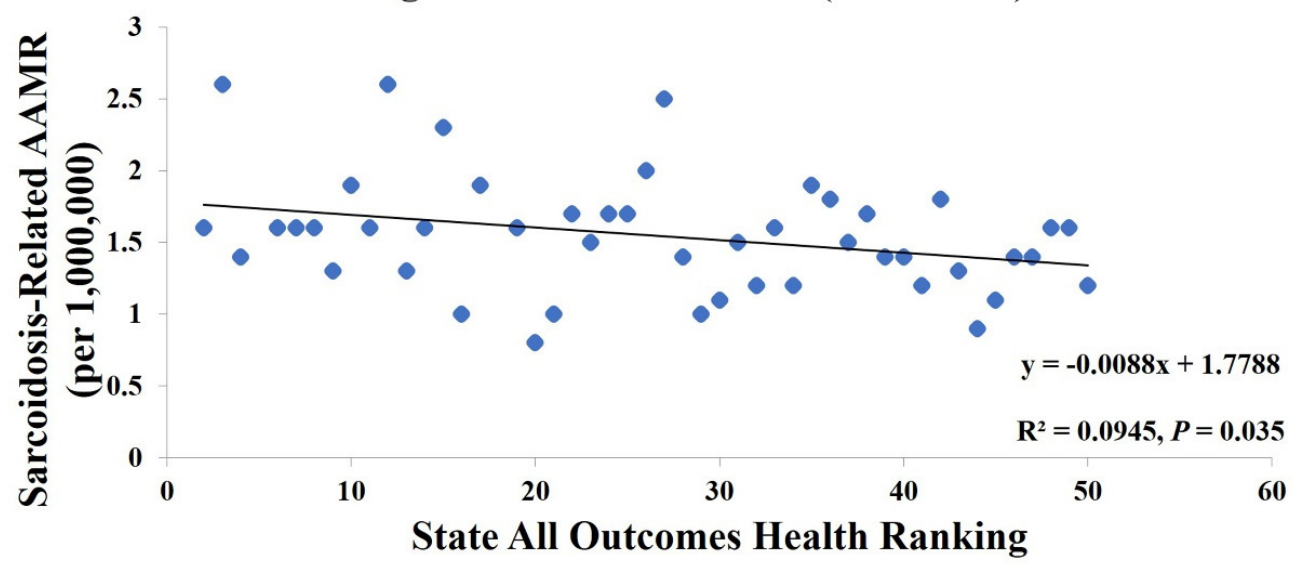

(C) Sarcoidosis-Related AAMR and All Determinants Health Ranking for 50 states of the US (1999-2018)

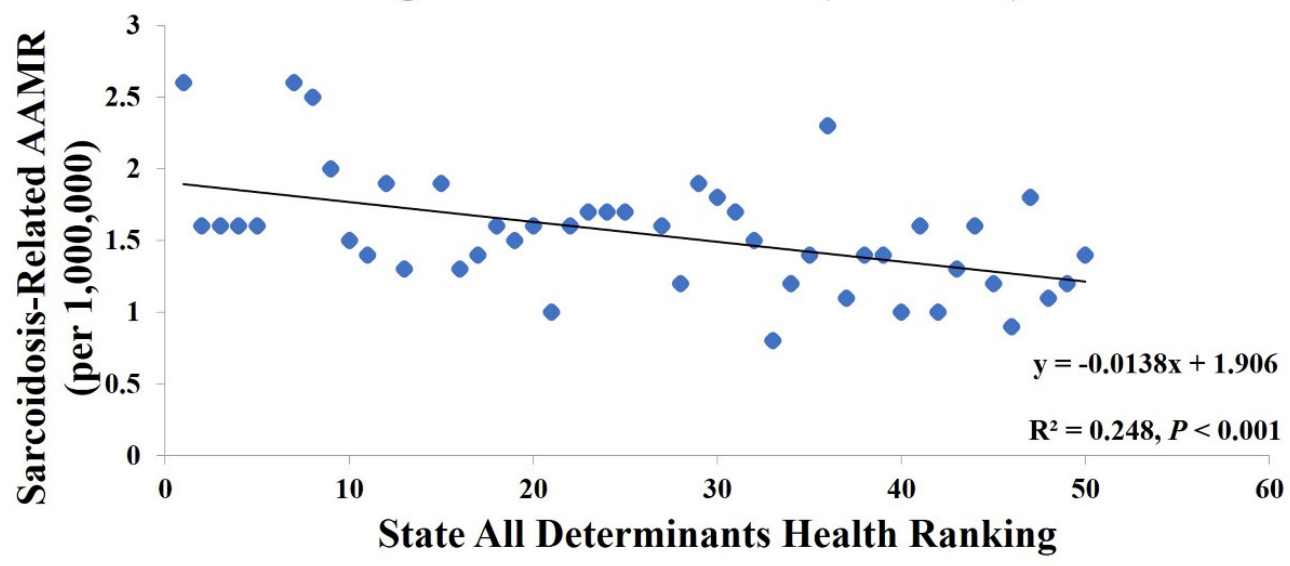

Figure 3. Sarcoidosis-Related AAMR in European Americans is significantly associated with (A) Overall Health Rankings, (B) All Outcomes Health Rankings, and (C) All Determinants Health Rankings. 
African Americans

(A) Sarcoidosis-Related AAMR and Overall Health Ranking

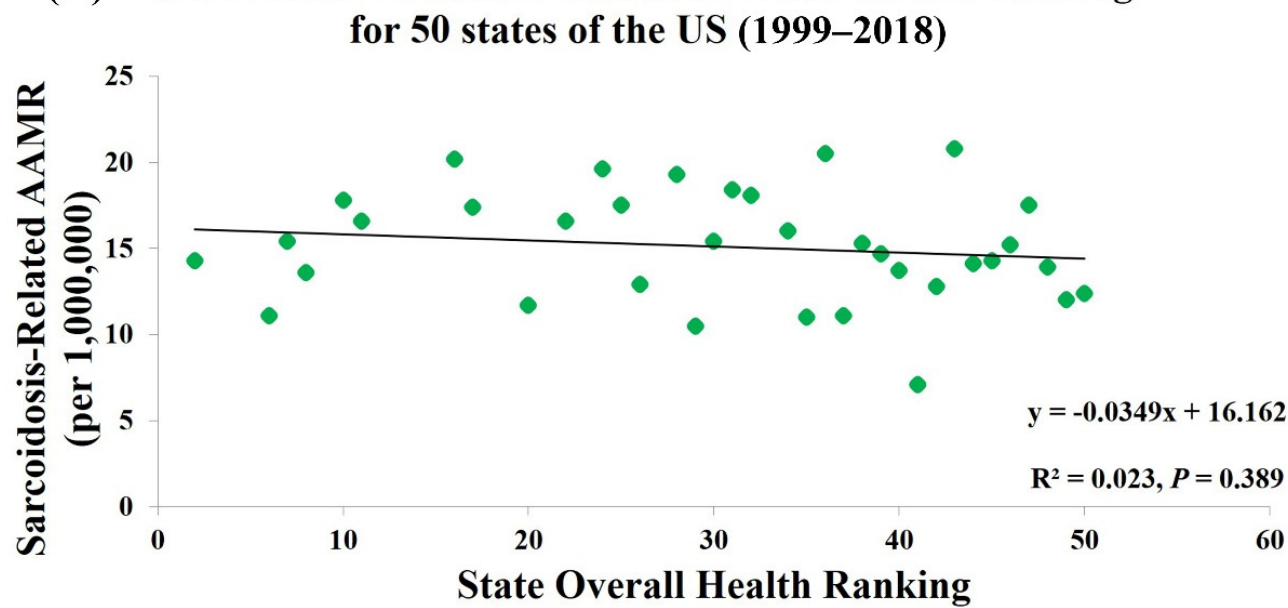

(B) Sarcoidosis-Related AAMR and All Outcomes Health Ranking for 50 states of the US (1999-2018)

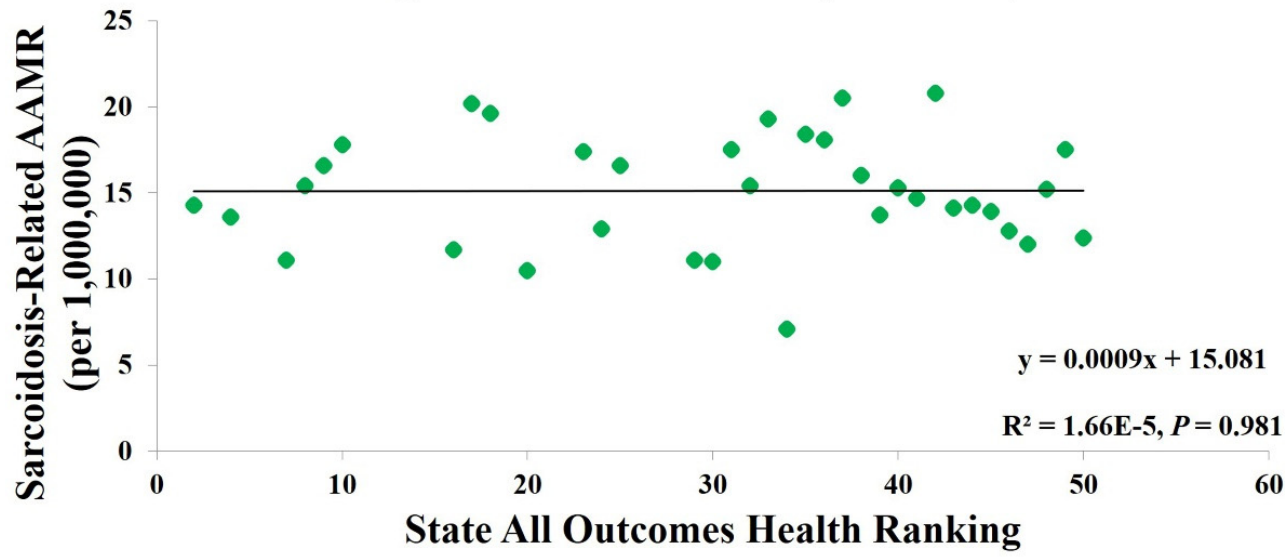

(C) Sarcoidosis-Related AAMR and All Determinants Health Ranking for 50 states of the US (1999-2018)

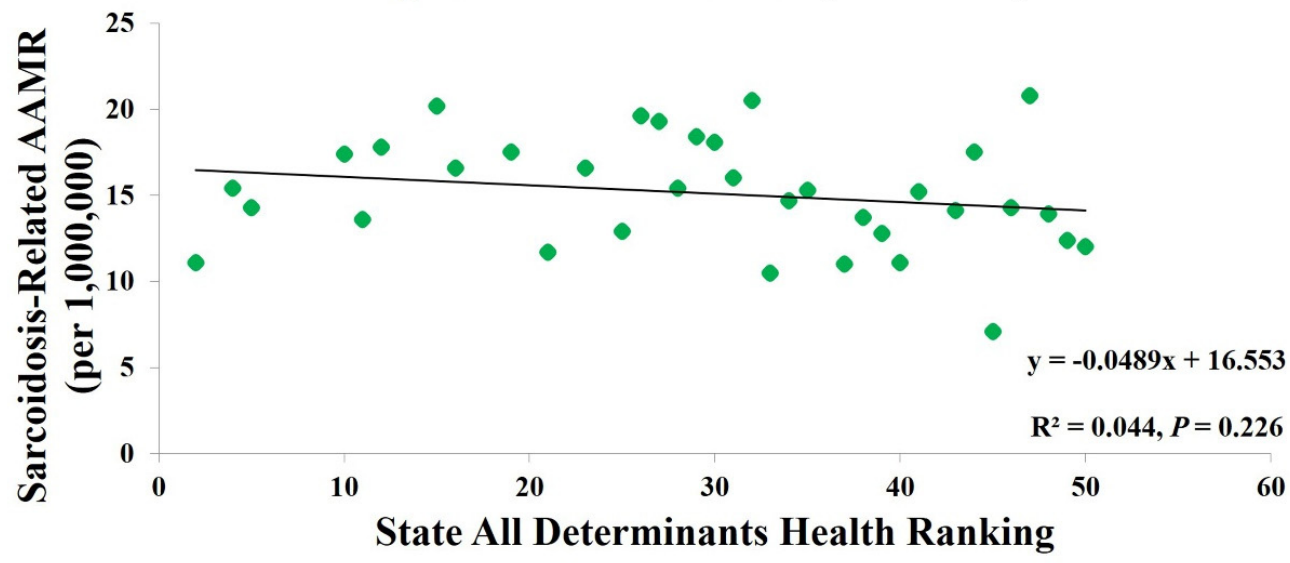

Figure 4. Sarcoidosis-Related AAMR in African Americans is not associated with (A) Overall Health Rankings, (B) All Outcomes Health Rankings, and (C) All Determinants Health Rankings. 
Table 2. Summary of Sarcoidosis-Related Age-Adjusted Mortality Rate and FSR-WASOG Sarcoidosis Clinics of 9 Geographic Divisions.

1999-2018

\begin{tabular}{ccccc} 
Geographic Division & \multicolumn{2}{c}{ Age-Adjusted Mortality Rate (AAMR) per 1,000,000 } & $\begin{array}{c}\text { FSR-WASOG } \\
\text { Sarcoidosis Clinics }\end{array}$ \\
\cline { 2 - 4 } & All Population & African Americans & European Americans & 3 \\
New England & 2.3 & 12.4 & 1.8 & 11 \\
Middle Atlantic & 3.4 & 15.2 & 1.6 & 10 \\
East North Central & 3.2 & 16.5 & 1.6 & 5 \\
West North Central & 2.1 & 14.3 & 1.3 & 13 \\
South Atlantic & 4.2 & 16.3 & 1.4 & 3 \\
East South Central & 3.7 & 14.6 & 1.1 & 8 \\
West South Central & 2.5 & 11.7 & 1.3 & 3 \\
Mountain & 1.5 & 10.6 & 1.2 & 3 \\
Pacific & 1.6 & 12.1 & & \\
\hline
\end{tabular}

\section{Discussion}

This study demonstrates geographic differences in sarcoidosis-related mortality in the US for 1999-2018, and to our knowledge, the first-ever assessment to evaluate the association between sarcoidosis-related AAMR and state-level health disparities. The mapping of sarcoidosis-related AAMR shows the different distribution for all populations, African Americans and European Americans. The highest AAMR for all populations was found in South Carolina, Maryland, and Alabama whereas the lowest in Arizona, New Mexico, and Nevada. For African Americans, the highest AAMR was seen in South Carolina, North Carolina, and West Virginia but the lowest in Nevada, Arizona, and Florida. In regard to European American, Northeastern states, including Vermont, Maine, and Rhode Island, had a higher AAMR than most southern states. These geographic findings are similar to the previous studies by Swigris et al. [3] and Mirsaeidi et al. [4], who both reported that sarcoidosis-related mortality rates were greater in some Northeastern states for European Americans.

Sarcoidosis-related mortality is affected by the management of long-term complications and the effectiveness of treatments including corticosteroids, cytotoxic drugs, and biologic agents [9-21]. State health rankings represent the availability and affordability of medical services and therapeutic options resulting in the disparity of health care by state. We found a positive association between state health rankings and sarcoidosis-related AAMR in all populations, indicating higher mortality rates in states with worse health rankings. Our model showed the highest correlation in All Outcomes health rankings, explaining $28.6 \%$ of the variability for AAMR, followed by Overall health rankings (16.9\%) and All Determinants health rankings (9.5\%). This significant association can be explained by attributing better All Outcomes health rankings to greater general health care capacities, which lead to better access to state-of-art medications, a higher quality of management for sarcoidosis-related complications, and lower mortality rates. Racial population distribution in the US, environmental exposures, occupational exposures, socioeconomic status, and public health programs and policies are also critical factors for sarcoidosis-related mortality [22-29]. Previous research showed sarcoidosis imposes a significant economic burden with considerable variations in healthcare spending on sarcoidosis patients in the US $[7,30,31]$. Baughman et al. indicated the median health care cost for patients with sarcoidosis was $\$ 18,663$ per year but the yearly cost for the top $5 \%$ was $\$ 93,201$ [7]. Similarly, Rice et al., in their study, found the average annual healthcare costs of high-cost sarcoidosis patients were 10 times that of the low-cost patients $(\$ 73,345$ vs. $\$ 7,073)$ [31]. The average annual healthcare costs were even higher for patients in the top $2-5 \%$ and top $1 \%$, at $\$ 119,878$ and $\$ 375,436$, respectively. Their study also identified several high-cost indicators, including complicated patients with higher rates of comorbidities, increased health care resource use (hospitalizations and specialty visits), and advanced treatments with biologic therapies (adalimumab and/or infliximab) [31]. Interestingly, Harper et al. recently also 
suggested low income was a leading predictor of poor outcome for sarcoidosis [32]. All these factors can be the reason that sarcoidosis-related AAMR in all populations was significantly associated with Overall and All Determinants health rankings.

There is a paradoxical association of state health rankings with sarcoidosis-related AAMR in European Americans. In our study, the Northeastern states have better health rankings, yet paradoxically higher mortality rates. One possible explanation is the heterogeneity in disease presentation and severity among different ethnic-racial backgrounds and the inconsistency of health care ability to identify the disease in different states. Establishing a definitive diagnosis for sarcoidosis can be challenging. Diagnosis of sarcoidosis is based on specific radiographic and pathologic findings in the setting of a compatible clinical presentation and exclusion of alternative diagnoses. A number of studies indicated European Americans tend to present with asymptomatic and chronic disease compared to African Americans [33-35]. This suggests states with better health rankings may have greater medical resources and abilities to identify chronic or asymptomatic patients, contributing to higher incidence, prevalence, and mortality rates for sarcoidosis. Diagnostic capacities and reporting sarcoidosis as primary or secondary causes of mortality is another major factor that might play a role.

FSR-WASOG Sarcoidosis Clinics are certified institutions that provide multidisciplinary care to patients with all forms of sarcoidosis. Among 50 states and 9 geographic divisions, New York State and South Atlantic have the largest numbers of FSR-WASOG Sarcoidosis Clinics (6 and 13, respectively). In the US, most Sarcoidosis Clinics are affiliated with university hospitals and built based on patients' needs. Therefore, the law of supply and demand is a key point that could explain the relationship between Sarcoidosis Clinics numbers and sarcoidosis-related AAMR, suggesting states with Sarcoidosis Clinics have higher AAMR in all population compared to those without Sarcoidosis Clinics and divisions with higher AAMR tend to have larger numbers of Sarcoidosis Clinics for all population and African Americans. Sarcoidosis Clinics visit advanced and complicated patients that are at higher risk of mortality.

There are some strengths and limitations to our study. The standardized methods and measures using national population-based surveillance and relatively easy website-based analysis tool to obtain the underlying cause of death data and state health rankings in the US are our strengths $[5,6]$. However, the mortality data are based on death certificates from the National Center for Health Statistics and there are intrinsic concerns and limitations related to the inconsistent report for the cause of death by clinicians, misclassification, and incorrect coding of diagnoses in the dataset [3-6]. Another limitation is the use of state health rankings and numbers of Sarcoidosis Clinics to represent the health care disparities in the US may not be specific. Although America's Health Rankings composes of five core measures (Behaviors, Community \& Environment, Policy, Clinical Care, and Outcomes) to evaluate the health care status of each state, there are still some crucial parameters not included. We did not have information for sarcoidosis incidence, prevalence, diagnostic capacity, disease severity, therapeutic resources, and comorbidities by state, which may play crucial roles in explaining the geographic differences of mortality rates. Therefore, further research and investigations are warranted to support our findings.

Overall, our study showed clear racial and geographic differences in sarcoidosisrelated AAMR in the US and its marked association with state health rankings and the numbers of Sarcoidosis Clinics. The current study suggests sarcoidosis-related AAMR could be an indicator to reflect the health care disparities between states and the improvement of overall health status in the US may also improve the mortality rates of sarcoidosis.

Supplementary Materials: The following are available online at https://www.mdpi.com/article/10 .3390/jcm10112366/s1, Figure S1: Map of (A) Overall Health Rankings, (B) All Outcomes Health Rankings, and (C) All Determinants Health Rankings for 50 States of the US, 1999 to 2018, Figure S2: Map of FSR-WASOG Sarcoidosis Clinics for 50 States of the US, Figure S3: Association Between FSR-WASOG Sarcoidosis Clinics and Sarcoidosis-related AAMR for (A) All Population, (B) African Americans, and (C) European Americans. 
Author Contributions: Y.-C.L. had full access to all the data in the study and takes responsibility for the integrity of the data and the accuracy of the data analysis. Y.-C.L. and M.M. contributed to the literature review, study concept and design, data analysis and interpretation. Y.-C.L., K.-Y.C., and M.M. contributed to the writing and revision of the manuscript. All authors have read and agreed to the published version of the manuscript.

Funding: This research received no external funding.

Institutional Review Board Statement: Not applicable.

Informed Consent Statement: Not applicable.

Data Availability Statement: All relevant data are within the manuscript and its Supporting Information files.

Acknowledgments: The authors would like to thank the Centers for Disease Control and Prevention, America's Health Rankings, World Association for Sarcoidosis and Other Granulomatous Disorders, and the Foundation for Sarcoidosis Research for providing the dataset.

Conflicts of Interest: Yu-Che Lee and Ko-Yun Chang declare no conflicts of interest. Mehdi Mirsaeidi is awarded a research grant from Mallinckrodt and is an advisory board member for Mallinckrodt pharmaceutical. No potential conflicts of interest exist with any companies/organizations whose products or services may be discussed in this article.

\section{Abbreviations}

AAMR Age-Adjusted Mortality Rates

AHR America's Health Rankings

FSR Foundation for Sarcoidosis Research

WASOG World Association for Sarcoidosis and Other Granulomatous Disorders

\section{References}

1. Iannuzzi, M.C.; Fontana, J.R. Sarcoidosis: Clinical presentation, immunopathogenesis, and therapeutics. JAMA 2011, 305, 391-399. [CrossRef]

2. Cozier, Y.C. Assessing the worldwide epidemiology of sarcoidosis: Challenges and future directions. Eur. Respir. Soc. 2016, 48, 1545-1548. [CrossRef] [PubMed]

3. Swigris, J.J.; Olson, A.L.; Huie, T.J.; Fernandez-Perez, E.R.; Solomon, J.; Sprunger, D.; Brown, K.K. Sarcoidosis-related mortality in the United States from 1988 to 2007. Am. J. Respir. Crit. Care Med. 2011, 183, 1524-1530. [CrossRef] [PubMed]

4. Mirsaeidi, M.; Machado, R.F.; Schraufnagel, D.; Sweiss, N.J.; Baughman, R.P. Racial difference in sarcoidosis mortality in the United States. Chest 2015, 147, 438-449. [CrossRef] [PubMed]

5. Kearney, G.D.; Obi, O.N.; Maddipati, V.; Mohan, A.; Malur, A.; Carter, J.C.; Thomassen, M.J. Sarcoidosis deaths in the United States: 1999-2016. Respir. Med. 2019, 149, 30-35. [CrossRef]

6. Ogundipe, F.; Mehari, A.; Gillum, R. Disparities in Sarcoidosis Mortality by Region, Urbanization, and Race in the United States: A Multiple Cause of Death Analysis. Am. J. Med. 2019, 132, 1062-1068.e3. [CrossRef]

7. Baughman, R.P.; Field, S.; Costabel, U.; Crystal, R.G.; Culver, D.A.; Drent, M.; Judson, M.A.; Wolff, G. Sarcoidosis in America. Analysis based on health care use. Ann. Am. Thorac. Soc. 2016, 13, 1244-1252. [CrossRef] [PubMed]

8. Gerke, A.K.; Judson, M.A.; Cozier, Y.C.; Culver, D.A.; Koth, L.L. Disease burden and variability in sarcoidosis. Ann. Am. Thorac. Soc. 2017, 14 (Suppl. 6), S421-S428. [CrossRef]

9. Baughman, R.P.; Lower, E.E. Who dies from sarcoidosis and why? Am. Thorac. Soc. 2011, 183. [CrossRef]

10. Bargagli, E.; Olivieri, C.; Rottoli, P. Cytokine modulators in the treatment of sarcoidosis. Rheumatol. Int. 2011, 31, 1539-1544. [CrossRef] [PubMed]

11. Baughman, R.; Lower, E.; Drent, M. Inhibitors of tumor necrosis factor (TNF) in sarcoidosis: Who, what, and how to use them. Sarcoidosis Vasc. Diffus. Lung Dis. 2008, 25, 76-89.

12. Baughman, R.P.; Grutters, J.C. New treatment strategies for pulmonary sarcoidosis: Antimetabolites, biological drugs, and other treatment approaches. Lancet Respir. Med. 2015, 3, 813-822. [CrossRef]

13. Cremers, J.P.; Drent, M.; Bast, A.; Shigemitsu, H.; Baughman, R.P.; Valeyre, D.; Sweiss, N.J.; Jansen, T.L. Multinational evidencebased World Association of Sarcoidosis and Other Granulomatous Disorders recommendations for the use of methotrexate in sarcoidosis: Integrating systematic literature research and expert opinion of sarcoidologists worldwide. Curr. Opin. Pulm. Med. 2013, 19, 545-561. [CrossRef] [PubMed]

14. Paramothayan, S.; Lasserson, T.J.; Walters, E.H.; Paramothayan, N.S. Immunosuppressive and cytotoxic therapy for pulmonary sarcoidosis. Cochrane Database Syst. Rev. 2001. [CrossRef] 
15. Schutt, A.C.; Bullington, W.M.; Judson, M.A. Pharmacotherapy for pulmonary sarcoidosis: A Delphi consensus study. Respir. Med. 2010, 104, 717-723. [CrossRef] [PubMed]

16. Baughman, R.; Lower, E. Fungal infections as a complication of therapy for sarcoidosis. QJM 2005, 98, 451-456. [CrossRef] [PubMed]

17. Baughman, R.; Nagai, S.; Balter, M.; Costabel, U.; Drent, M.; Du Bois, R.; Grutters, J.; Judson, M.; Lambiri, I.; Lower, E. Defining the clinical outcome status (COS) in sarcoidosis: Results of WASOG Task Force. Sarcoidosis Vasc. Diffus. Lung Dis. 2011, 28, 56-64.

18. Baughman, R.; Winget, D.; Bowen, E.; Lower, E. Predicting respiratory failure in sarcoidosis patients. Sarcoidosis Vasc. Diffus. Lung Dis. Off. J. WASOG 1997, 14, 154-158.

19. Baughman, R.P.; Engel, P.J.; Taylor, L.; Lower, E.E. Survival in sarcoidosis-associated pulmonary hypertension: The importance of hemodynamic evaluation. Chest 2010, 138, 1078-1085. [CrossRef]

20. Gribbin, J.; Hubbard, R.B.; Le Jeune, I.; Smith, C.J.; West, J.; Tata, L.J. Incidence and mortality of idiopathic pulmonary fibrosis and sarcoidosis in the UK. Thorax 2006, 61, 980-985. [CrossRef] [PubMed]

21. Chappell, A.; Cheung, W.; Hutchings, H. Sarcoidosis: A long-term follow up study. Sarcoidosis Vasc. Diffus. Lung Dis. Off. J. WASOG 2000, 17, 167-173.

22. Bartter, T.; Irwin, R.S.; Abraham, J.L.; Dascal, A.; Nash, G.; Himmelstein, J.S.; Jederlinic, P.J. Zirconium compound-induced pulmonary fibrosis. Arch. Intern. Med. 1991, 151, 1197-1201. [CrossRef]

23. Mangiapan, G. Mycobacteria and sarcoidosis: An overview and summary of recent molecular bilological data. Sarcoidosis 1995, $12,20-37$.

24. Werfel, U.; Schneider, J.; Rodelsperger, K.; Kotter, J.; Popp, W.; Woitowitz, H.; Zieger, G. Sarcoid granulomatosis after zirconium exposure with multiple organ involvement. Eur. Respir. J. 1998, 12, 750. [CrossRef] [PubMed]

25. Cai, H.-r.; Min, C.; Meng, F.-q.; Wei, J.-y. Pulmonary sarcoid-like granulomatosis induced by aluminum dust: Report of a case and literature review. Chin. Med. J. 2007, 120, 1556-1560. [CrossRef] [PubMed]

26. Izbicki, G.; Chavko, R.; Banauch, G.I.; Weiden, M.D.; Berger, K.I.; Aldrich, T.K.; Hall, C.; Kelly, K.J.; Prezant, D.J. World Trade Center "sarcoid-like" granulomatous pulmonary disease in New York City Fire Department rescue workers. Chest 2007, 131, 1414-1423. [CrossRef] [PubMed]

27. Jordan, H.T.; Stellman, S.D.; Prezant, D.; Teirstein, A.; Osahan, S.S.; Cone, J.E. Sarcoidosis diagnosed after September 11, 2001, among adults exposed to the World Trade Center disaster. J. Occup. Environ. Med. 2011, 53, 966-974. [CrossRef] [PubMed]

28. Newman, L.S.; Rose, C.S.; Bresnitz, E.A.; Rossman, M.D.; Barnard, J.; Frederick, M.; Terrin, M.L.; Weinberger, S.E.; Moller, D.R.; McLennan, G. A case control etiologic study of sarcoidosis: Environmental and occupational risk factors. Am. J. Respir. Crit. Care Med. 2004, 170, 1324-1330. [CrossRef] [PubMed]

29. Balmes, J.R.; Abraham, J.L.; Dweik, R.A.; Fireman, E.; Fontenot, A.P.; Maier, L.A.; Muller-Quernheim, J.; Ostiguy, G.; Pepper, L.D.; Saltini, C. An official American Thoracic Society statement: Diagnosis and management of beryllium sensitivity and chronic beryllium disease. Am. J. Respir. Crit. Care Med. 2014, 190, e34-e59. [CrossRef]

30. Rice, J.B.; White, A.; Lopez, A.; Conway, A.; Wagh, A.; Nelson, W.W.; Philbin, M.; Wan, G.J. Economic burden of sarcoidosis in a commercially-insured population in the United States. J. Med. Econ. 2017, 20, 1048-1055. [CrossRef]

31. Rice, J.B.; White, A.; Lopez, A.; Nelson, W.W. High-cost sarcoidosis patients in the United States: Patient characteristics and patterns of health care resource utilization. J. Manag. Care Spec. Pharm. 2017, 23, 1261-1269. [CrossRef]

32. Harper, L.J.; Gerke, A.K.; Wang, X.-F.; Ribeiro Neto, M.L.; Baughman, R.P.; Beyer, K.; Drent, M.; Judson, M.A.; Maier, L.A.; Serchuck, L. Income and other contributors to poor outcomes in US patients with sarcoidosis. Am. J. Respir. Crit. Care Med. 2020, 201, 955-964. [CrossRef] [PubMed]

33. Newman, L.S.; Rose, C.S.; Maier, L.A. Sarcoidosis. N. Engl. J. Med. 1997, 336, 1224-1234. [CrossRef]

34. Rybicki, B.A.; Major, M.; Popovich, J., Jr.; Maliank, M.J.; lannuzzi, M.C. Racial differences in sarcoidosis incidence: A 5-year study in a health maintenance organization. Am. J. Epidemiol. 1997, 145, 234-241. [CrossRef] [PubMed]

35. Baughman, R.P.; Lower, E.E.; du Bois, R.M. Sarcoidosis. Lancet 2003, 361, 1111-1118. [CrossRef] 